\title{
A INTERVENÇÃO NA FFCL DE SÃO JOSÉ DO RIO PRETO EM 1964
}

\author{
Caroline Maria Florido $^{1}$
}

\begin{abstract}
RESUMO: Neste artigo realiza-se uma síntese das motivações da intervenção policial na Faculdade de Filosofia, Ciências e Letras (FFCL) de São José do Rio Preto - SP no primeiro dia da ditadura civil-militar em 1964. A partir desse dia, professores e estudantes da instituição foram presos e investigados com a abertura de um Inquérito Policial Militar. Essa foi a principal fonte histórica utilizada para a pesquisa, além de outros documentos e fontes bibliográficas, que reconstruiu a trajetória da instituição e levantou as causas da alteração de seus rumos após sete anos de sua existência. Conflitos entre frações de classes durante a sua criação, singularidade em seu projeto político pedagógico e organização institucional diferenciada teriam sido as causas da intervenção indicadas em outras referências históricas. Mas o estudo do IPM permitiu confirmar como principal motivo da prisão e perseguição de professores e estudantes seu envolvimento com os movimentos sociais e educacionais do período, considerados uma ameaça ao projeto das classes dominantes brasileiras.
\end{abstract}

Palavras-chave: História das instituições. Ditadura civil militar. Movimentos sociais.

\section{THE INTERVENTION IN THE FFCL OF SÃO JOSÉ DO RIO PRETO IN 1964}

ABSTRACT: This article makes a synthesis of the intervention police motivations at the Philosophy Sciences and Letters College (FFCL) of São José do Rio Preto-SP on the first day of the civil-military dictatorship, 1964. From that day, professors and students from the institution were arrested and investigated by a Military Police Inquiry (MPI). This was the main historical source used for the research, in addition to other documents and bibliographic sources, which rebuilt the trajectory of the institution and raised the causes of the alteration of its directions after seven years of its existence. Conflicts between fractions of classes during their creation, singularity in their political pedagogical project and differentiated institutional organization would have been the causes of the intervention indicated in other historical references. But the study of MPI allowed to confirm as the main reason for the arrest and persecution of teachers and students were their involvement with the social and educational movements of the period, considered a threat to the Brazilian dominant classes project.

Keywords: History of institutions. Military civilian dictatorship. Social movements.

\footnotetext{
${ }^{1}$ Mestre em Educação. Doutoranda em Educação pela Universidade Estadual de Campinas (UNICAMP). Campinas-SP/Brasil. Docente da Secretaria Municipal de Educação de Campinas-SP/Brasil. E-mail: cflorido01@gmail.com
} 


\section{LA INTERVENCIÓN EN LA FFCL DE SÃO JOSÉ DO RIO PRETO EN 1964}

RESUMEN: Este artículo proporciona una síntesis de las motivaciones de intervención policial en la Facultad de Ciencias, Filosofía y Letras (FFCL) de São José do Rio Preto - SP en el primer día de la dictadura civil-militar en 1964. A partir de ese día, los profesores y estudiantes de la institución fueron arrestados e investigados con la inauguración de una Encuesta de la Policía Militar (EPM). Esa fue la principal fuente histórica utilizada para la investigación, además de otros documentos y fuentes bibliográficas, que reconstruyeron la trayectoria de la institución y elevaron las causas de la alteración de sus direcciones después de siete años de su existencia. Los conflictos entre fracciones de clases durante su creación, la singularidad en su proyecto político pedagógico y la organización institucional diferenciada habrían sido las causas de la intervención indicada en otras referencias históricas. Pero el estudio del EPM permitió confirmar como la principal razón de la detención y persecución de docentes y estudiantes su implicación con los movimientos sociales y educativos de la época, considerados una amenaza al proyecto de las clases dominantes brasileñas.

Palabras clave: Historia de las instituciones. Dictadura civil militar. Movimientos sociales.

\section{Introdução}

Este artigo contempla uma síntese de dissertação concluída em 2013 que narra a história da Faculdade de Filosofia, Ciências e Letras (FFCL) de São José do Rio Preto, instituição de ensino superior do interior de São Paulo, sob o olhar da intervenção civil militar no dia 10 de abril de 1964. Após a intervenção, professores e estudantes da instituição foram submetidos a um Inquérito Policial Militar (IPM), investigação e perseguição que mudaram os rumos da faculdade e de suas vidas.

A FFCL de São José do Rio Preto, ou apenas FAFI, como era conhecida, nasceu em 1957 e, em 1964, encerrou seu primeiro ciclo de vida. A história da instituição foi explorada em outros estudos acadêmicos pela relevância histórica dessa primeira fase de sua existência.

Para a realização da pesquisa levantaram-se fontes históricas relevantes, relativas a esses sete primeiros anos de existência, assim como informações importantes para a reconstrução de sua história antes de 1957 e após 1964. Nesse sentido, optou-se pela priorização de uma fonte ainda não explorada em outros estudos: o Inquérito Policial Militar (IPM), processo aberto na ocasião da intervenção a fim de investigar as atividades consideradas "subversivas" realizadas por professores e estudantes. 
Essa documentação foi disponibilizada pelo grupo de História e Política Educacional da UNESP de São José do Rio Preto, coordenado pela professora Silvana Fernandes Lopes. A administração da UNESP possuía uma cópia do inquérito desde 1997, mas ela estava incompleta. A professora foi autorizada, então, a digitalizar o processo em 2009, nos arquivos do Superior Tribunal Militar. A reconstituição da história da instituição, articulando fontes anteriormente utilizadas com fontes inéditas, permitiu expor com maior rigor determinados conflitos de interesses entre as classes que a disputavam e, consequentemente, explicar quais teriam sido os motivos reais para mudarem seu rumo.

Quando se iniciou a pesquisa, pairavam várias dúvidas e mistificações a respeito da repressão sofrida pela FFCL de São José do Rio Preto. Perguntava-se: por que ela teria sido a primeira instituição de ensino superior (ou pelo menos uma das primeiras) a sofrer intervenção das forças militares? Por que alguns professores e estudantes foram presos, processados e tiveram seus futuros completamente desviados? Quais teriam sido as forças externas e internas à FAFI que determinaram as acusações de subversão? Como foi o cenário repressivo em relação ao que aconteceu às demais instituições de ensino superior no estado e no país? A faculdade teria mesmo sido um "centro irradiador do comunismo", como se propagava no período e após a intervenção? Mas buscava-se, principalmente, responder: Por que o projeto da FFCL de São José do Rio Preto seria tão ameaçador para a ordem vigente, a ponto de a instituição ter sido praticamente desmontada em 1964, imediatamente após a instalação do regime ditatorial?

A pesquisa que originou a referida dissertação dedicou-se principalmente à investigação das causas da intervenção ditatorial na FFCL de São José do Rio Preto. Para além de explicar o caso de São José do Rio Preto, buscava-se também entender os motivos pelos quais ocorreram intervenções em outras instituições de ensino superior no país. De acordo com a historiografia da FAFI, as causas primárias da intervenção seriam as disputas na criação da FFCL e o caráter inovador do projeto político pedagógico da instituição. A despeito dessas conclusões, a principal causa indicada no IPM e aprofundada no estudo foi o envolvimento de professores e estudantes com os movimentos educacionais e populares do período.

A pesquisa iniciou-se em 2011 e a dissertação foi concluída em 2013, contexto no qual a ditadura civil militar era foco de novas produções acadêmicas, pela proximidade dos 50 anos 
pós-golpe civil militar, como também pelas autorizações oficiais de abertura dos arquivos e a criação de comissões que averiguaram a história de instituições educacionais, grupos políticos e indivíduos envolvidos nos conflitos contra o regime ditatorial, principalmente como forma de investigação sobre pessoas desaparecidas, torturadas e mortas. Desde a Lei da Anistia, em 1979, os familiares e amigos dos desaparecidos e assassinados durante a ditadura civil militar (1964-1985) lutam pela abertura dos arquivos referentes ao período. Alguns dos documentos começaram a ser disponibilizados em arquivos públicos para consulta, mas muitos daqueles referentes a prisões e torturas continuam sob a guarda sigilosa dos militares.

Em 2012, foi instaurada a "Comissão da Verdade"2, uma investigação ampla dos arquivos que abrangem o período de 1946 a 1988, a fim de levantar e tornar públicas as ocorrências de violação dos direitos humanos nesse período. Os governos do Partido dos Trabalhadores (PT), principalmente a partir do primeiro mandato de Dilma Roussef (20102014), comprometeram-se em averiguar, criar novos registros e fortalecer a memória contra a ditadura, evidenciando as injustiças cometidas pelo Estado brasileiro ao longo de décadas de perseguição política, repressão e tortura.

Ao olhar para a história da FFCL de São José do Rio Preto, não pairam dúvidas sobre a importância do estudo das instituições escolares no campo da História da Educação. Fruto de inúmeras determinações, próprias de seu tempo histórico, a FAFI trazia em seu projeto a expressão da disputa entre classes antagônicas. Apesar de produzir e reproduzir as condições econômicas, sociais e culturais dominantes, assim como outras instituições de ensino superior, tornou-se palco de contradições e contestações à ordem vigente, influenciando na construção de novas mentalidades ou na manutenção de velhas ideologias, agindo conjuntamente com movimentos sociais ou auxiliando em sua desqualificação, dando base científica e fomentando as diversas formas de exploração no capitalismo, assim como criticando-o e combatendo-o no campo intelectual (FLORIDO, 2013).

Além disso, a história da FAFI de São José do Rio Preto expõe a discussão sobre a relação dos projetos políticos e pedagógicos de instituições brasileiras de ensino superior frente às necessidades da classe trabalhadora. Em seu início, a FAFI foi reduto de alguns professores e estudantes que se preocupavam em construir seu conhecimento de forma

\footnotetext{
${ }^{2}$ A Lei 12.528/2011, que a instituiu, foi sancionada em 18 de novembro de 2011 e a comissão foi instalada oficialmente em 16 de maio de 2012. Informações encontradas no site Memórias Reveladas.
} 
crítica, pensando na pedagogia não apenas como produto do sistema produtivo, mas como instrumento de contraposição às injustiças sociais e culturais.

Tomando-se a particularidade da experiência da FAFI, dentro de uma dinâmica contestatória à ordem vigente, presente nos movimentos sociais e educacionais do início dos anos 1960, buscou-se resgatar sua "singularidade" entre outras instituições brasileiras de ensino superior e situar sua condição dentro do panorama da transição para o período ditatorial, quando a intelectualidade deixou de ter protagonismo no ensino e na pesquisa. Assim como no período no qual a pesquisa encerrou-se, faz-se necessário, na atualidade, expor a materialidade das tentativas de superação de aspectos históricos das instituições burguesas e avaliar quais teriam sido os elementos reformadores e/ou revolucionários, nas experiências sepultadas pelas ações autoritárias do Estado brasileiro

Cabe relembrar, como indica Florestan Fernandes (1975, p. 10-11), que as respostas para novas indagações frente ao processo de reformas sucessivas que se deram no ensino superior durante a ditadura civil militar, encontrar-se-iam "nas ideias e soluções que foram condenadas como subversivas", como é o caso da experiência vivida na FFCL de São José do Rio Preto. Apesar de uma "transição lenta e gradual" para um "Estado democrático" e mais de trinta anos depois do término do regime, o Brasil ainda não conseguiu equacionar alguns problemas como o elitismo e conservadorismo nas relações interinstitucionais no ensino superior e vigoram, cada vez mais, a burocratização e o produtivismo no meio acadêmico, sejam estas instituições estatais ou particulares.

Em tempos de golpes institucionais, projetos de Escola sem Partido e "delinquência acadêmica" ${ }^{3}$ nas universidades brasileiras, tratar da intervenção da FAFI de São José do Rio Preto em 1964 torna-se uma atualidade. O tempo, por vezes, parece brincar com a história e muito do que se viu há mais de cinquenta anos volta a acontecer como "fatos", por vezes descontextualizados ao modo pós-moderno de se construir a história. Nesse sentido, buscase aqui trazer a materialidade histórica do passado para se entender o conservadorismo das elites brasileiras e suas garras ideológicas até o momento presente.

\footnotetext{
${ }^{3}$ Referência ao artigo "Delinquência Acadêmica", escrito em por Maurício Tragtemberg e apresentado no I Seminário de Educação Brasileira, realizado em 1978, em Campinas. Tragtemberg foi um dos docentes detidos e demitidos após abertura do IPM em São José do Rio Preto
} 


\section{Um estudo da história institucional à luz de um inquérito policial?}

A dissertação que deu origem a este artigo foi construída a partir da análise de fontes primárias e secundárias disponibilizadas pelo grupo de História e Política Educacional Brasileira, da Universidade do Estado de São Paulo (UNESP) de São José do Rio Preto, assim como de textos jornalísticos, acervos pessoais de professores e trabalhos acadêmicos anteriores. Realizou-se - levantamento, leitura e sistematização de documentos institucionais: atas de departamentos e entidades, regimentos, processos e portarias internas, manifestos e legislação do período, publicações e registros pessoais dos professores e de entidades estudantis. Inúmeros documentos foram consultados na Seção de Comunicações do Instituto de Biologia, Letras e Ciências Exatas (IBILCE), como é conhecido atualmente o campus da UNESP em São José do Rio Preto. Avaliou-se também toda a bibliografia disponível referente ao tema - teses, dissertações, artigos acadêmicos e jornalísticos.

Mas a documentação analisada mais relevante foi o Inquérito Policial Militar (IPM) aberto a partir de 1을 de abril de 1964, na circunstância da intervenção da Faculdade e da instalação do regime civil-militar, quando foram indiciados professores e estudantes da FAFI. A pesquisa configurou-se então em um desafio analítico de fontes pouco utilizadas nos estudos historiográficos. O IPM contém mais de 2000 páginas e é constituído por "peças" como depoimentos, relatórios, autos e documentos organizados de acordo com uma lógica legal e jurídica, da qual não se detinha conhecimento técnico para análise. Buscou-se, portanto, analisar as informações condizentes com as perguntas e as relações históricas consideradas relevantes contidas no corpo do processo.

Para entender o trabalho com esse tipo de fonte, buscou-se na literatura referências a respeito de seu uso e verificou-se que os IPM foram instrumentos criminais existentes antes mesmo de 1964 e previstos no Código de Justiça Militar. Eram abertos com a finalidade de se instalar um processo sumário, em que os envolvidos eram indiciados por atividades ilícitas, sem direito à defesa e julgados em um curto período de tempo. Existentes desde a ditadura varguista, esses inquéritos funcionavam como dispositivos de perseguição política, principalmente contra os comunistas.

Com a instalação do regime civil-militar de 1964, os IPM foram indiscriminadamente utilizados pela Justiça Militar como estratégicos no "controle das áreas políticas, militares e 
psicossociais". Wanderley $(2009$, p. 8) denomina essa estratégia como "Operação Limpeza", que funcionando por tempo limitado, agiria como mecanismo de controle social até que o Estado militar se institucionalizasse de fato. A autora ainda completa:

O decreto-lei n. 53.897 de 27 de abril de 1964 regulamentava os IPMs previstos pelo primeiro ato institucional. Estes inquéritos constituíram um mecanismo legal para a busca sistemática de segurança absoluta e a eliminação do inimigo interno, tornando-se uma fonte de poder de fato para o grupo de militares designados para chefiar e coordenar suas investigações (WANDERLEY, 2009, p. 8-9).

O IPM n. 183/64 é o processo criminal no qual se insere a sindicância da FFCL de São José do Rio Preto, junto a outras três que foram criadas assim que os militares tomaram o poder. Depois de algum tempo, o processo ganhou status próprio, separando-se dos demais, oferecendo uma compilação de documentos e depoimentos, dentro de um contexto de caça àqueles chamados pelos militares "inimigos da ordem democrática". Na ocasião da intervenção foram apreendidos jornais, cartas, pastas, livros, panfletos, boletins, manifestos, todo o material existente nas sedes das entidades estudantis, o Centro Acadêmico de Filosofia (CAF) e no Movimento Popular de Cultura (MPC), além da casa do professor Franz Wilhelm Heimer e no pensionato onde moravam estudantes que participavam do MPC. Da apreensão de documentos na casa do professor Heimer, apresentam-se correspondências, planejamentos, orientações e textos bases para a constituição da Ação Popular (AP) no Brasil, os quais indicavam concepções políticas e filosóficas para a construção da organização.

Esse corpo de documentos apreendidos e a forma como ele foi interpretado pela ordem vigente constituíram-se nas peças que faltavam para montar um quebra-cabeças para as argumentações das classes dominantes locais que tentavam provar como a FAFI teria se tornando um "centro comunizador" no interior paulista. No entanto, o próprio inquérito, quando se contrapõem os depoimentos com os documentos, mostra-se insuficiente para provar "atos subversivos" e configura-se principalmente em uma desmoralização e criminalização de práticas educacionais que defendiam as reformas de base e as propostas políticas em disputa do período. Mesmo insuficiente do ponto de vista racional jurídico, em consonância com o Ato Institucional n. 1, ele foi o instrumento que faltava para justificar a demissão dos professores e afastamento dos estudantes, além de instaurar posteriormente um clima de ameaça e silenciamento dentro da instituição. 
Os IPM são fontes históricas pouco conhecidas e exploradas, pois sua disponibilização para consultas foi dificultada até os anos 1990. Controlados pelo Superior Tribunal Militar, alguns processos têm sua consulta restrita, outros continuam como arquivos sigilosos, mesmo com as recentes aberturas dos arquivos promovidas por legislação do Executivo. Os IPM foram realizados em todos os estados brasileiros e aqueles que não foram destruídos, continuam resguardados pelas normas de segurança nacional, reservando grande quantidade de documentos que expõem as feridas do atrelamento do Judiciário com o Executivo militarizado.

De acordo com Scocuglia (2006, p. 3-4), essas fontes seriam importantes para se reconstruir a história do regime civil-militar, pois explicitavam "a fúria legalista dos golpistas no poder", buscando "demonstrar e justificar as acusações contra parlamentares, estudantes, professores, jornalistas, comunistas, religiosos, advogados, agricultores, políticos etc. como inimigos da pátria condenáveis por suas opiniões, escritos, trabalhos, pregações, livros e propostas". O autor utilizou-se de um IPM como fonte para estudar o fechamento da Campanha de Educação Popular (CEPLAR), na Paraíba, comparando seus documentos com outras fontes disponíveis (depoimentos, artigos jornalísticos, fontes orais e escritas, públicas e privadas). Em seu estudo certificou que esses acervos foram indicadores da criminalização de agentes e militantes de organizações populares, mesmo que estes não possuíssem qualquer vínculo com o comunismo, ou inclusive, fossem avessos às ideias e práticas comunistas. Configuraram-se como processos arbitrários, contando com a oposição de vários juristas até o estabelecimento do Ato Institucional n. 5, em 1968.

\section{Suspensão da história da FAFI? A acusação e a abertura do Inquérito}

O regime civil militar impôs-se ao Brasil na madrugada do dia 31 de março de 1964. As tropas militares de Minas Gerais deslocaram-se para o Rio de Janeiro a fim de garantir que não houvesse resposta do governo federal. No Rio Grande do Sul, Rio de Janeiro e Rio Grande do Norte, esboçaram-se reações de alas políticas e militares contra o golpe, sem reação civil ou mesmo de orientação governamental. No dia 1으 de abril instalava-se o novo regime, com o apoio do empresariado e dos meios de comunicação. Logo noticiaram que o presidente João Goulart havia rumado para o exílio no Uruguai, sendo o governo assumido provisoriamente 
pelo vice Ranieri Mazilli. Três dias após o golpe, o governo dos Estados Unidos anunciou apoio ao regime e, em 11 de abril, o Congresso Nacional forjou a eleição do Marechal Castelo Branco para a Presidência da República.

Imediatamente, a Junta Militar começou a ajustar o Estado de acordo com a Doutrina de Segurança Nacional e baixou o Primeiro Ato Institucional, dentre tantos que viriam. De acordo com o Ato Institucional n. 1, "distanciado o governo que pretendia bolchevizar o país", as forças armadas se responsabilizavam, então, pela realização das eleições para a presidência. Além disso, subordinavam os poderes do Congresso Nacional à presidência e mantinham a Constituição Federal de 1946. O Al -1 previa também a "suspensão, por pelo menos seis meses, dos direitos constitucionais de estabilidade e vitaliciedade", ou seja, oficializava as demissões e aposentadorias em quaisquer cargos públicos ou militares para aqueles que fossem julgados ameaças à "segurança do País, ao regime democrático e à probidade da administração pública".

A lei possibilitava, ainda, a abertura de inquéritos para "os crimes contra o Estado ou de seu patrimônio e a ordem política e social ou de atos de guerra revolucionária", com a suspensão de direitos políticos por dez anos e cassação de mandatos. O Al-1 entrou em vigor no dia 9 de abril de 1964, vigorando "teoricamente" até janeiro de 1966, quando assumisse o novo presidente da república que, supostamente, seria eleito em outubro de 1965.

Sentindo-se no dever de cumprir com os propósitos da instauração de uma ordem que livrasse o país da "ameaça comunista", os militares instalaram nas instâncias governamentais e nas instituições estatais um rígido controle quanto a qualquer manifestação de contrariedade ao novo regime. Instauraram em todo o Brasil os IPM e fortaleceram as divisões oficiais de investigação política - Departamentos de Ordem Política e Social (DEOPS). Denúncias e delações se multiplicaram, fazendo as cadeias ficarem cheias de presos políticos, considerados "inimigos da ordem e ameaça à segurança nacional". Os movimentos indígenas, dos trabalhadores rurais, movimentos sindical e estudantil sofreram duramente com a repressão, prisão e perseguição de suas lideranças durante todo o regime militar. Intelectuais e professores das instituições de ensino superior foram os primeiros alvos de acusações de subversão.

Na FFCL de São José do Rio Preto, essa realidade foi mais precoce do que a entrada em 
vigor do Al-1. No dia 10 de abril de 1964, mal o golpe se instaurara, a faculdade sofreu uma intervenção policial. Enquanto os estudantes realizavam uma assembleia convocada pelo Centro Acadêmico de Filosofia (CAF) para discutir se dariam apoio ao presidente deposto, João Goulart, a polícia entrou na faculdade e interrompeu suas atividades, alegando várias denúncias. A Faculdade foi fechada, estudantes e professores foram detidos e deu-se início a uma sindicância transformada em IPM levada a cabo pela polícia local.

O projeto da instituição, que tentava se configurar como "inovador", foi definitivamente encerrado pela demissão do diretor João Dias da Silveira, substituído pelo juiz da 2a Vara Criminal e interventor José de Castro Duarte. Colocando em prática todo o plano de controle e enquadramento da instituição às leis e normas vigentes, o diretor-interventor designou desde cedo uma comissão para elaborar um novo regimento para a Faculdade.

Nos meses que se seguiram, até se completarem as investigações, foram detidos para averiguações os seguintes professores: Franz Wilhelm Heimer, Flávio Vespasiano Di Giorgi, Casemiro dos Reis Filho, Hélio Leite de Barros, Orestes Nigro, Jacob Liebenszteyn, Newton Ramos de Oliveira, José Aluysio Reis de Andrade, Maurício Tragtenberg, João Jorge da Cunha, Joacyr Badaró, José de Arruda Penteado. Foram ainda indiciados e considerados foragidos Wilson Cantoni, Maria Edith do Amaral Garboggini, Mary Amazonas Leite de Barros, Sarah Rottemberg, Norman Maurice Potter. Foi presa junto a Heimer sua esposa, Maria de Lourdes Heimer, que não era oficialmente professora na Faculdade, mas coordenava o Movimento Popular de Cultura.

Os estudantes e ex-estudantes detidos foram: Ledercy Gigante (3 ano de Pedagogia), Vlademir Moscheta ( $2 \circ$ ano - Letras), Pedro Bonilha Regueira Filho (2ำ ano - Letras), Edson Guiducci, Nair dos Santos (3 ano - Letras), Nilo Sérgio Moreira Scrochio (10 ano - Pedagogia), Mary Gil Barrinuevo (2ㅇ ano - Pedagogia), Mara Ramos (3ㅇ ano de Letras), Edson Raposeiro (ex-estudante), Ruy Quirino Guimarães (ex-estudante), Grigor Vartanian (2ำ ano - História Natural), Cleide Ignês Polachini (2o ano de Letras), Hevelin Galvan (ex-estudante), Vera Lúcia Crivelenti ( 3 ํ ano - História Natural), Yurie Tsuda (4ํano - História Natural), Maria Aparecida de Lacerda Mezzena (3 ano - História Natural), Marisa Jorge Ramos (3ano de História Natural), Nildenir Ferreira de Carvalho ( 30 ano de Letras), José Murilo Farinazzo (exestudante), Mário Odivil Maia (ex-estudante), Yvone Spolon (3o ano de Letras), Oflaviano 
Martins Rodrigues (ex-estudante), Gigante, João Paulo de Oliveira Neto (2o ano de Pedagogia), Eudete Focchi (3o ano de Pedagogia), Maria de Lourdes Cápua (4o ano de Pedagogia), Maria Isabel Cápua (3ำ ano de Pedagogia), Aparecida Barcos Soler (3ํano de Pedagogia), Maria Edna Mugayar (4ㅇano de Pedagogia), Nilza Moreno (3o ano - Letras).

Foram interrogados como testemunhas os ex-diretores Raphael Grisi e João Dias da Silveira, os professores Daud Jorge Simão, Celso Abbade Mourão, Luiz Dino Vizotto, Giorgio de Marinis, Fahad Moisés Arid, Paulo Nogueira de Camargo (ESALQ), Edoardo Querin, Osvaldir Francisco Castro, Samir Felício Barcha, Hermione Elly Melara de Campos Bicudo, Aluísio José Gallo e Zélia Rodrigues Ramozzi; os funcionários Walter Guimarães de Andrade Fogaça (secretário), Durval Dias Barbosa, Osvaldo de Paula e Paulo Martins (motoristas), Osvaldo Correa da Rocha (almoxarife), Assay Nakagawa (eletricista). As estudantes Yvone de Moura Campos Almeida (3ㅇ ano de Pedagogia), Amélia Fernandes de Souza (2o ano de Pedagogia), Chafic Balura (3ㅇ ano de Pedagogia), Érica Moreira Sandemberg (3 ano de Pedagogia), Flávia Gerônima Pereira (3o ano de Pedagogia), Zahia Cais (3o ano de Pedagogia) testemunharam espontaneamente (alguns levaram cadernos como provas).

De fora da faculdade entraram Laerte Paulo Fávero e Olavo Verzola Demarco, funcionários da Superintendência da Reforma Agrária (SUPRA), Inês Hirata, funcionária do Serviço Social Rural (SSR); Ary Neves da Silva (ex-aluno), Telmo Maia (livreiro), Ethevaldo Melo de Siqueira (sindicalista bancário), Antonio Funari Filho (estudante de Direito em Ribeirão Preto), Oscar Luiz Ramos Pires (professor da Faculdade D. Pedro II). Além desses, entraram seis trabalhadores rurais da fazenda Nossa Senhora Aparecida, do município de Mirassol, pertencente a Olavo Fleury Filho.

A Justiça Militar colocou como acusados professores e estudantes pelos crimes previstos pela lei n. 1.802 de Segurança Nacional, de 5 de janeiro de 1953, que "define os crimes contra o Estado e a Ordem Política e Social", enquadrando-os nos seguintes artigos:

Art. 9o - Reorganizar ou tentar reorganizar, de fato ou de direito, pondo logo em funcionamento efetivo, ainda que sob falso nome ou forma simulada, partido político ou associação dissolvidos por força de disposição legal ou fazê-lo funcionar nas mesmas condições quando legalmente suspenso;

Art. 12 - Incitar diretamente e de ânimo deliberado as classes sociais à luta pela violência" (BRASIL, LEI N. 1802, 1953) 
A autuação foi registrada após investigação iniciada em 1ำ de abril e concluída no dia 13 de outubro de 1964, no cartório de 1 o ofício de São José do Rio Preto, depois de ter sido avaliada pela promotoria e julgada pelo Ministério Público Estadual. Nas primeiras páginas do processo, consta que o Ministério Público Militar qualificava Franz W. Heimer, Maria de Lourdes Heimer, Ledercy Gigante, Flávio Vespasiano Di Giorgi, Orestes Nigro, Hélio Leite de Barros, Newton Ramos de Oliveira e Wilson Cantoni, além das seguintes informações:

Com exclusão de Ledercy Gigante, todos eles professores da Faculdade de Filosofia, Ciências e Letras de São José do Rio Preto, neste estado, que a seguir, pelos fatos passa a expor na cidade acima referida, quando da eclosão do movimento revolucionário de 1964 e consequente levantamento das práticas subversivas ocorrentes no país, no seio da Faculdade de Filosofia, fulcro de toda a vida intelectual mais elevada da região, foram constatados fatos gravíssimos, envolvendo nomes de parte dos professores, alguns dos quais com implicação intensa. Sob as denominações de Centro Popular de Cultura - Ação Popular, Grupo Artístico de Teatro Amador (GRUTA), restaurava-se e era posto em funcionamento, quer veladamente, quer de forma meridiana, o PC (Partido Comunista), que, espraiando-se para as fazendas, penetrando nos ambientes rurais, levava a palavra de Moscou, disfarçada em teatro ou alfabetização de adultos. Tanto é verdade, que até mesmo o nome dos mais conhecidos agitadores comunistas (para exemplo, Jofre Correia Neto), ora aqui, ora ali, apareciam para solidificar o planejamento. Apreendida a documentação (apostilas, panfletos, volantes, pasquins, libretos, opúsculos, cartas) nas sedes das entidades referidas, patenteou-se não serem elas simples veículos de cultura popular ou atividades extracurriculares da Faculdade de Filosofia. Causou profunda impressão surgirem figuras de relevo da Igreja Católica imiscuídas com agitadores vulgares. Inocentes úteis visando o bem-estar social, a redenção das massas obreiras, solidificação dos liames familiares, uniram suas atividades a dos Emissários da Internacional Comunista, sempre viva, sem perceber que solapavam a própria Família, a própria Igreja. Verifique a documentação de fls. 31/32, 97/117, 470 e centenas de outras, onde do cristianismo só restou o termo e do comunismo a essência. Como já este promotor afirmou, seria extremamente útil que fosse levado aos católicos mal informados o pensamento dos comunistas a seu respeito: máquina de terraplanagem a abrir as largas estradas das correntes vermelhas, que, uma vez cumprida a missão, serão eliminadas como escória prejudicial, ou no máximo, convertidas em sucata social" (BRASIL, v. 1, p. 2-4, 1971, grifo da pesquisadora).

Em seguida, o relatório de qualificação dos crimes afirmava quais seriam os papéis de cada um dos acusados: Heimer como chefe ("general”) do grupo, sua esposa Maria de Lourdes como secretária do MCP, Ledercy seria "hábil comunista" que, ao lado de Newton, buscaria 
"jogar o camponês contra o fazendeiro", Flávio Di Giorgi seria o homem culto e inocente (teria dado palestras em sindicatos), Nigro como chefe do GRUTA - grupo de teatro que teria feito apresentações aos operários; Hélio, que "pretendia civilizar os caboclos, mas nos moldes soviéticos"; Newton teria usado vários recursos para levar suas "pregações revolucionárias" aos trabalhadores rurais e Cantoni seria confesso comunista (com uma afirmação sobre o comunismo de Cantoni ser uma convicção). Como testemunhas principais aparecem Daud Jorge Simão, Yvone de Moura Campos Almeida, Euclides Palacani, Sebastião José da Rocha, Adelino Delamoura, Laércio Palacani, Ethevaldo de Melo Siqueira e outras Edoardo Querin, Nildenir Ferreira Carvalho, Mauro Adevil Maia, Grigor Vantanian e Casemiro dos Reis Filho.

A rescisão do contrato dos professores Franz W. Heimer, Orestes Nigro, Newton Ramos de Oliveira, João Jorge Cunha, Flávio V. Di Giorgi, Wilson Cantoni, Sarah Rottemberg e Joacyr Badaró foi feita no dia 20 de maio de 1964. O professor Maurício Tragtenberg, também docente da instituição, teve seu contrato rescindido em julho de 1964. As demissões dos mesmos de seus cargos foram publicadas em 9 de outubro de 1964, assinadas pelo Governador Adhemar de Barros.

Consideradas as devidas limitações de veracidade quanto às informações obtidas no inquérito policial, por seu caráter de registro de investigação sob coerção, foram analisados os depoimentos e documentos arquivados com cuidado, confrontando-os com as informações antes registradas e documentadas em outros trabalhos e fontes institucionais. As páginas do processo com informações históricas mais relevantes a respeito do período e dos motivos pelos quais a FFCL de São José do Rio Preto teria sofrido a intervenção, no entanto, não são aquelas que contêm depoimentos dos acusados e testemunhas, mas sim, as que expõem documentos das organizações, apreendidos nas sedes do CAF e MCP e em arquivos pessoais dos professores processados.

Esse material foi considerado fonte histórica privilegiada, pelo seu teor de detalhes quanto ao funcionamento e propósitos das organizações que atuavam na difusão da cultura popular e no trabalho de base com os trabalhadores. Algumas delas são inéditas e raras, pois boa parte de documentação equivalente foi perdida ou destruída pelos próprios militantes dos movimentos que foram perseguidos no período e precisavam eliminar qualquer prova ou vestígios de suas ligações com as organizações de esquerda. Infelizmente, não se pôde 
aprofundar em sua exploração durante a pesquisa de mestrado pela limitação de tempo.

As páginas do processo contêm muitas informações e indicações históricas a respeito da intervenção militar na FAFI, como também detalhes sobre o contexto histórico, influências teóricas e práticas pedagógicas da instituição. Além disso, constatou-se por meio de depoimentos e notícias de jornal, como também pela dissertação de Oliveira $(1989$, p. 205206), que os resultados da interrupção no projeto da instituição e a perseguição que se desencadeou na cidade foram determinantes para o futuro dos professores, estudantes e funcionários que nela se mantiveram ou que dela foram expurgados, ficando estes sob vigilância por todo o período da ditadura. Por muito tempo depois da intervenção, os docentes e discentes da FAFI continuaram sendo considerados suspeitos de ligação com movimentos subversivos de âmbito nacional e internacional.

Um dos aspectos investigados no IPM foram as circunstâncias da criação e organização da FFCL de São José do Rio Preto. As testemunhas e acusados foram inquiridos sobre o processo de construção do projeto da instituição, mas, principalmente, foram levados a expor as divergências políticas e pedagógicas entre os grupos de professores, fatos que teriam sido determinantes para a interrupção do projeto em curso.

\section{De um instituto isolado a referência político cultural do interior paulista}

O projeto de lei de criação da FFCL de São José do Rio Preto é datado de 1955, mas a faculdade, por inúmeras disputas e discussões locais e conjunturais só iniciou suas atividades em 1957. Abrigou-a, então, o Instituto de Educação Monsenhor Gonçalves, tendo implantados primeiro os seguintes cursos: Pedagogia (35 vagas), Letras Anglo-Germânicas (35 vagas), Letras Neolatinas (35 vagas) e História Natural (25 vagas). Tinha disponível uma sala para a biblioteca e outra para a secretaria em um dos andares do Instituto.

A partir de 1957 iniciou-se uma campanha para sua estadualização, concluída em 1959, quando passou a compor o grupo de Institutos Isolados do Ensino Superior do Estado de São Paulo. Em 1958, os estudantes passaram a se organizar pelo Centro Acadêmico de Filosofia (CAF) e em 1961 surgiu o Grupo Artístico de Teatro Amador (GRUTA). Lopes e Sparvoli (2011, p. 98-99) confirmam que o movimento estudantil da FAFI, organizado pelo CAF, exerceu um papel importante na campanha de estadualização da faculdade, com um reconhecido mérito 
no engajamento no movimento nacional e nas questões ligadas à Faculdade.

Assim, algumas questões puderam ser relacionadas às encontradas no IPM da FFCL. Nos diversos depoimentos e documentos apresentados pelas testemunhas, a FFCL de São José do Rio Preto foi levada a cabo por iniciativa do vereador Daud Jorge Simão, que com o apoio de setores da burguesia e pequena-burguesia local, se imbuiu de fontes legais e políticas para legitimar o projeto de uma "universidade municipal". Mas ele encontrou inúmeros entraves econômicos e históricos, num contexto em que o Conselho Nacional de Educação (CNE) e o Conselho Estadual (CEE) se opunham à criação de novas universidades públicas. Dentro de uma proposta reduzida, se não representassem pretensões de formação para a elite dirigente, os projetos eram permitidos e incentivados. Nesse sentido, as Faculdades de Filosofia constituíram parte significativa do projeto educacional para o ensino superior, desde que mantivessem um caráter de formação profissional restrita e dividiam as profissões em função das classes às quais serviriam. Caso fossem bem apropriadas pelas classes dominantes locais, poderiam ser expandidas até que se tornassem, de fato, universidades. Se não, lograriam padecer como institutos isolados.

Portanto, diferente do apresentado no estudo de Attab (1973, p. 15-18), ao se analisar os documentos de criação da faculdade em um contexto amplo, pode se considerar a instituição não apenas um "fenômeno local", adequado aos interesses dos grupos políticos influentes da cidade, que argumentavam a importância de dar ao município nova condição cultural e status social frente ao desenvolvimento paulista, ou mesmo, que a iniciativa de políticos e intelectuais locais culminavam na proposta de um projeto pioneiro. A FAFI era mais uma instituição interiorana que expressava as contradições do período populista, em que as pressões regionais e locais, por vezes, se confrontavam ao mesmo tempo em que convergiam com as políticas para o ensino superior estadual e nacional.

De acordo com o panorama histórico do período, no qual se generalizavam as políticas populistas, as FFCL representavam um projeto educacional que tinham em sua concepção original não apenas o papel de instituições formadoras das elites locais, mas também eram concebidas como fontes irradiadoras da ideologia liberal e avanço civilizatório nos centros urbanos, importantes nichos eleitorais e de alianças políticas. Com a ampliação do alcance da imprensa, as discussões sobre as propostas políticas disputadas entre os diferentes grupos das 
classes dirigentes serviam tanto como canal ideológico, como para concorrer por verbas e benefícios estatais, que garantiam suas bases eleitorais e econômicas. As "universidades", ou as faculdades isoladas, representariam status intelectual e símbolo de poder econômico para a burguesia nacional, além de instrumento político e oportunidade de formação dos jovens, na crescente disputa pelo domínio do aparato estatal.

Vaidergorn (1995) relata que, desde o início de seu funcionamento até sua estadualização, a FAFI organizou-se política e didaticamente de forma diferenciada de outras instituições de ensino superior e se empenhava para não ser mais um "instituto isolado", inserindo-se nos debates e movimentos reformadores. Durante os anos 1959 e 1961, a instituição se envolveu nas discussões a respeito da Lei de Diretrizes e Bases da Educação (LDB), o que culminou na adesão de boa parte do seu corpo docente e do CAF à Campanha em Defesa da Escola Pública. Como a instituição sofria com as implicações diretas das políticas públicas estaduais e nacionais para o ensino superior, professores e estudantes construíam não apenas no discurso, uma experiência que respaldasse uma proposta de Reforma Universitária: organizava-se por departamentos, tinha representação paritária em alguns espaços e promovia inúmeras atividades extracurriculares, sendo esta, mais tarde, considerada a dimensão extensionista da universidade.

Com o aporte financeiro dos dois Planos de Ação do governo estadual e com a direção de João Dias da Silveira, a FAFI conseguiu se estruturar e organizar melhor a partir de 1962. Os professores, entusiasmados com os resultados das primeiras turmas formadas e com alguma experiência acumulada quanto à organização departamental e à articulação com os estudantes na parte didática-administrativa, impulsionaram um projeto que passou a sustentar, na posição deste estudo, a verdadeira singularidade da instituição. De acordo com a principal hipótese da pesquisa, aquilo que alguns autores chamaram de "experiência de reforma universitária" não teria sido o principal motivo de seu desmantelamento com o golpe civil militar. O fato que teria sido mais relevante como justificativa para a intervenção foi a institucionalização de um projeto político pedagógico de formação de professores articulado com os movimentos sociais e populares, com críticas à formação social brasileira.

No IPM da FAFI de São José do Rio Preto, os aspectos mais explorados nos depoimentos dos acusados de subversão pelos militares foram o envolvimento de professores e estudantes 
nos seguintes movimentos educacionais: projetos de alfabetização popular, realização de eventos político-culturais contestatórios e relação das práticas pedagógicas e culturais da faculdade com as críticas aos projetos dominantes. No inquérito, os militares exigem que todos os acusados e testemunhas contem se tinham relação com as atividades do MCP e o GRUTA, com políticos e organizações de esquerda e, principalmente com um movimento de trabalhadores rurais de Santa Fé do Sul. Eles teriam causado furor nas ruas da cidade na ocasião de uma manifestação da Campanha em Defesa da Escola Pública e conferência do professor Florestan Fernandes. Mas o inquérito explora de forma específica a relação de estudantes e professores com a Ação Popular (AP), organização de esquerda considerada "perigosa" no contexto de efervescência político-cultural do período.

A articulação com os movimentos sociais se deu em vários momentos, desde a estadualização da FAFI, e compôs uma preocupação política e pedagógica fundamental: materializar como função do ensino superior a defesa do acesso a toda população brasileira à educação pública, laica, gratuita e de qualidade. Para tanto, estudantes e professores se envolveram, principalmente, em três movimentos: na Campanha em Defesa da Escola Pública, por ocasião das discussões da Lei de Diretrizes e Bases (LDB), promulgada em 1961; No movimento pela Reforma Universitária, dentro das Reformas de Base, construído desde o final dos anos 1950 e que continuou mesmo após o golpe de 1964 até 1968, quando foi instituída a Reforma Universitária sob as leis do regime; no Movimento de Cultura Popular promovido pelo Movimento Estudantil e pela Ação Popular, junto à política da Juventude Universitária Católica (JUC) nacional e internacional.

\section{Projeto político-pedagógico transformado em crime}

Os anos anteriores à instalação da ditadura civil-militar foram marcados por intensas disputas no campo ideológico. As instituições e grupos empresariais que desejavam manter o país integrado ao capital monopolista, a fim de salvaguardar os acordos comerciais e financeiros com outros países, construíram um poderoso aparato político e midiático que disseminava a aversão ao comunismo e fortalecia a política de Segurança Nacional. Junto aos Estados Unidos, esses grupos estabeleceram programas e estratégias de guerra para o combate ao que considerassem ameaçador à ordem vigente, inclusive, criando um ambiente 
hostil à presidência de João Goulart. A burguesia nacional, completamente integrada ao sistema de acumulação e internacionalização do capital, tentava barrar o avanço organizativo e de politização que atravessava a classe trabalhadora, a qual questionava diretamente para onde iam tantas riquezas produzidas se existiam tamanhas desigualdades no campo e na cidade.

A Guerra Fria trazia consigo a disputa pela dominação econômica e política mundial entre os blocos capitalista e socialista, enquanto nos países onde o capitalismo havia crescido e começava a entrar em crise, como no Brasil, a classe trabalhadora questionava o imperialismo e o internacionalismo na economia. Uma onda nacionalista, mesmo dentro da esquerda, tomou conta daqueles que queriam ver o país mudar e imbuídos de um espírito reformista, clamavam por medidas estatais mais contundentes. Os projetos de desenvolvimento nacional estavam em disputa e a reação seguia no encalço dos movimentos estudantil, operário e camponês, que se articulavam cada vez mais por meio dos movimentos de cultura popular, os quais por mais revolucionários que parecessem, defendiam conjunturalmente as Reformas de Base como via para a transformação da realidade brasileira. Fortalecer o estado democrático e nacional parecia a saída para os trabalhadores, os quais aos poucos davam conta de que o capitalismo monopolista no Brasil estava plenamente consolidado.

Os Estados Unidos, interessados em barrar o avanço das forças de esquerda na América Latina, investiam financeira e tecnicamente nestes países, estabelecendo oficialmente "ajuda" pelo acordo chamado "Aliança para o Progresso", a partir de 1961, componente da política anticomunista de John F. Kennedy. Esse acordo foi travado após a Carta de Punta Del Este, na qual várias nações latino-americanas convergiram em um pacto de superação do subdesenvolvimento. Ele, no entanto, permitia que os EUA interferissem nas políticas sociais desses países e fomentava o fortalecimento do capitalismo.

Dreifuss (1981, p. 80-81) expõe também que a Escola Superior de Guerra, um dos eixos de formação de intelectuais militares e que ocupavam posições e cargos políticos chave, teria sido a principal instituição responsável pela formação e constituição ideológica dos grupos que instalaram o regime civil-militar em 1964. Por compartilhar de interesses com as empresas multinacionais, pois boa parte dos militares detinha capital financeiro e fundiário 
no Brasil, os intelectuais da Escola Superior de Guerra foram treinados nos EUA e tinham como função garantir que não houvesse conflitos entre qualquer tipo de cooperação Brasil-EUA com as "forças subversivas". Além disso, o autor relata o papel do Programa de Assistência Militar, que visava assegurar a "existência de forças militares e paramilitares suficientes para combater a subversão comunista, a espionagem, a insubordinação e outras ameaças à segurança interna".

Ainda de acordo com o mesmo autor, recorde-se que outras formas organizacionais defenderam os interesses civis e militares empresariais nesse período de construção de um projeto tecnocrático. Com interesses comuns, elas seriam as responsáveis pela "quebra ou esvaziamento do corporativismo associativo", típico do sistema populista. Essas organizações seriam os escritórios tecnoempresariais (Consórcio Brasileiro de Produtividade - CBP, Companhia Sul-Americana de Administração e Estudos Técnicos - CONSULTEC), associações de classe empresariais renovadas (Federação das Indústrias do Estado de São Paulo - FIESP, Centro de Indústrias do Estado de São Paulo - CIESP, American Chambers of Commerce, Conselho Nacional de Classes Produtoras - CONCLAP, Associação Brasileira das Indústrias de Base - ABDIB) e grupos de ação com o propósito de defesa da "modernização conservadora", como o Instituto Brasileiro de Ação Democrática (IBAD). O IBAD junto ao Instituto de Pesquisas e Estudos Sociais (IPES) foram as instituições anticomunistas que produziam material, financiavam com dinheiro norte americano, particular e público, e nas quais se formava uma intelectualidade que realizava pesquisas com o objetivo de combater o ideário do Instituto de Sociologia e Estudos Brasileiros (ISEB) e de outras frentes desenvolvimentistas, assim como para perseguir as organizações de esquerda.

A articulação militar-empresarial se dava também no campo político parlamentar, no qual os partidos de maioria nos governos eram a União Democrática Nacional (UDN) e o Partido Social Democrático (PSD), sendo principalmente o primeiro composto por empresários, latifundiários e banqueiros, representantes dos interesses do grande capital e dos quais vários deles ocupavam altas e médias patentes militares. Esses aparatos se articularam dentro e fora das instituições estatais ditas "democráticas" para construir uma paranoia quanto à possibilidade de um golpe comunista, que seria levado a cabo pelo Partido Comunista Brasileiro (PCB) e outras organizações de esquerda e legitimado pela presidência 
de João Goulart. Esses argumentos teriam “justificado" a intervenção militar em 1964, como forma de manutenção da "ordem democrática nacional" e de afastamento de um "governo comunista".

As manifestações massivas se multiplicavam tanto na ala de defesa das reformas e direitos dos trabalhadores como na defesa dos costumes tradicionais e da propriedade privada. Essa polarização ficou expressa em duas grandes mobilizações: no Comício de Jango na Central do Brasil, no Rio de Janeiro, em 13 de março de 1964, em que reuniram milhares de pessoas em defesa das reformas de base; e na Marcha da Família com Deus pela Liberdade, de 19 de março, em São Paulo, que também concentrou aproximadamente 500 mil pessoas das classes média e alta, mobilizadas pelas associações femininas com o apoio do IPES e do governo de Adhemar de Barros, contra o comício de João Goulart. Além disso, de acordo com Dreifuss (1981), a burguesia golpista havia montado frentes de estudos nos anos anteriores, amparadas nas pesquisas do IPES e IBAD que ampliaram seu aporte ideológico frente às reformas de base propostas pelo governo. Portanto, o reformismo foi combatido como se fosse uma das expressões do comunismo, pois as Reformas de Base eram pontos convergentes do apoio das oposições e grupos de esquerda ao governo Jango.

Depois de meses de propaganda anticomunista e de defesa do patriotismo, construindo uma base social e política para assumirem o poder, os militares amparados pelo empresariado resolveram agir: no dia 31 de março, partindo de Juiz de Fora (MG), o General Mourão Filho mobilizou suas tropas para seguirem rumo à capital do país. Esse fato levou as forças armadas a se orientarem para ficarem alertas a qualquer reação do governo João Goulart e acionarem até mesmo tropas norte-americanas, que estavam dispostas na costa brasileira para assegurar o golpe. Não foi preciso agir, pois as instituições estatais brasileiras logo ficaram cientes do novo estado autoritário e Jango se retirou para o exílio.

Em São José do Rio Preto, as investidas conservadoras aos movimentos sociais não foram diferentes e a FAFI representava um núcleo no qual todos os movimentos se aglutinavam ou se viam representados nas atividades do CAF, GRUTA e MCP. A Faculdade tornou-se imediato alvo dos golpistas, que sabendo da atuação desses grupos dentro da instituição e na região, não esperaram qualquer esboço de organização dos professores e estudantes para agirem. Autoridades locais articuladas com as forças policiais esperavam o 
momento oportuno para intervir no projeto da instituição. Construída a ideia de que a Faculdade guardava a atuação de grupos "comunistas" organizados, expressa nas falas e meios de comunicação locais, publicizadas nas ruas e nos lares dos familiares dos estudantes e influenciada ideologicamente pelo contexto geral, não houve oposição quanto à invasão do prédio e à prisão de professores e estudantes.

As denúncias de subversão que sobrevieram a essa situação foram acolhidas pelos militares, que tinham a seu favor a Lei de Segurança Nacional. Mas as denúncias formais parecem ter vindo de contribuidores e inimigos de longa data: as primeiras testemunhas de acusação foram Daud Jorge Simão, os professores Celso Abbade Mourão e Luiz Dino Vizotto, antigos opositores internos do grupo de professores que dirigiam as mudanças políticopedagógicas na FFCL. Estudantes de orientação conservadora também aproveitaram a situação para delatar professores e colegas de curso envolvidos no movimento estudantil.

Ao se ter contato com o IPM que investigou o caso da FFCL de São José do Rio Preto, percebe-se uma articulação anterior à intervenção, pois, no dia 10 de abril, a polícia já estava preparada para invadir a faculdade, prendendo várias pessoas. Logo em seguida, invadiu a sede do MPC, do CAF, do GRUTA e a casa do professor Franz W. Heimer. Nesses locais foram apreendidos todos os documentos, livros, cartas, cartazes e panfletos dos grupos. Os autos de busca e apreensão desses locais, assim como os documentos sobre a AP foram propositalmente colocados na abertura do processo, para justificar o indiciamento de Heimer como mentor e líder dos projetos subversivos existentes na faculdade. Essa informação se explicita no parecer que encerra o primeiro volume do processo, no qual o delegado José Domingos Ferreira encaminha para o DEOPS de São Paulo, no dia 24 de abril de 1964, o pedido de acompanhamento do processo por terem se confirmado a existência de "atividades subversivas na FAFI". O texto diz o seguinte.

As diligências encetadas para a apuração de possíveis práticas subversivas por professores da Faculdade de Filosofia desta cidade de São José do Rio Preto, nesta altura, já permitem admitir que o movimento de AP, desenvolvido nesta entidade estudantil, por alguns professores e coordenado pelo professor Franz Heimer, já se encontrava em fase de ação, quer através do MPC e GRUTA, órgãos dos estudantes locais.

Quanto ao propósito subversivo, basta dizer que esse movimento outro fim não possuía se não transformar a estrutura sócio econômica 
do país, até mesmo pela violência. A simples consulta de seu documento base e de boletins distribuídos por esse órgão, a simples declaração do professor Franz e do Sr. Ethevaldo de Mello de Siqueira, e finalmente o apoio que tal movimento recebia dos órgãos federais, então subordinados ao Sr. Jango Goulart, revelam quão sérias seriam as consequências desse movimento (BRASIL, v. 1, p. 248, 1971).

Pela diversidade de questões sobre a FAFI expostas nos depoimentos, poderiam ser extraídas várias linhas de investigação, mas as principais referências se dão em torno da hipótese de que a FFCL abrigava um grupo de professores articulados ao PCB e ao governo de João Goulart, os quais coordenariam os estudantes em atividades em prol da "transformação da sociedade brasileira para o regime comunista". Mas, apesar das delações e afirmações das testemunhas sobre a ligação das atividades de Heimer e do MPC com a AP, além da confirmação de ex-estudantes do CAF e GRUTA às propostas de reformas de base, percebe-se uma exposição sobre o enredo no qual se reforçava a ideia de que estas organizações seriam realmente perigosas e estariam muito bem organizadas e armadas, prontas para uma insurreição, a ponto de ameaçarem a ordem local e nacional.

No entanto, quando se analisa mais detidamente os documentos da AP e os depoimentos dos volumes subsequentes, percebe-se que os militares não obtiveram concretamente provas de tais fatos. Não provam que esses movimentos teriam conseguido uma inserção nos meios operários ou dos trabalhadores rurais, a ponto de avançarem na mobilização, agitação e organização dos trabalhadores contra a ordem burguesa, muito menos de que estariam armados e preparados para qualquer revolta.

A pesquisa permitiu o acesso a inúmera quantidade de documentos disponíveis a respeito da história da FAFI de São José do Rio Preto, os quais contam de forma complexa, como se deram os conflitos e disputas antes, durante e depois da intervenção da ditadura empresário civil-militar na instituição. No entanto, priorizou-se responder por que essa intervenção se deu e por que foi tão imediata à instalação do regime ditatorial. Percebeu-se, diante disso, que antes mesmo do desmonte da Faculdade, a mídia e alguns representantes das classes dominantes locais preocuparam-se em construir uma "mística" em torno da instituição, disseminando que a mesma era um "centro comunizador" na região, que tinha professores atuantes em movimentos políticos de esquerda e que doutrinavam os estudantes contra as instituições democráticas. Assim como o IPES e o IBAD, a burguesia e a intelectualidade conservadora local se apropriaram bem dos meios de comunicação para 
difundir a desqualificação da esquerda, enquadrando a FAFI dentro dessa doutrinação.

Não era propósito da pesquisa realizar o relato dos depoimentos e testemunhos contidos no IPM, pois a intenção não era discutir o quão comunistas seriam ou não os professores e estudantes da FAFI e se eles admitiram suas posições aos policiais. Mas por fim, considerou-se o quanto esses depoimentos poderiam ser úteis para mostrar o entendimento dos professores e estudantes de suas ações políticas como sendo subversivas, ou mesmo, do quanto seus envolvimentos com os movimentos sociais e educacionais poderiam ser usados contra sua "liberdade de cátedra" ou de "pensamento".

Para a maior parte dos professores e estudantes indiciados, os debates e envolvimento nos processos educativos e reivindicativos faziam parte de uma nova proposta de formação de cursos superiores, dentro de uma democracia, na qual se exercia o livre pensar e expressar, em que se defendia a igualdade de condições e direitos de ensino e aprendizagem da cultura nacional. O fato de serem veiculadas notícias e correrem boatos quanto à faculdade ser comunista causava desconforto em alguns, mas desagradava principalmente aos professores que foram acusados de subversão, pois se defenderam como nacionalistas e/ou social democratas.

Esse jogo político de desqualificação do projeto institucional em curso durante os primeiros anos de existência da FAFI foi a forma encontrada por autoridades locais de retomarem o controle da instituição, perdido quando a mesma deixou de ser municipal para tornar-se estadual, em que não vigoravam as influências diretas da burguesia local. E mesmo os governos estadual ou federal se isentaram da responsabilidade quanto à existência da FAFI, colocando-a numa condição de auto sustentação ou morte. Quanto "mais pública e menos estatal" a faculdade se tornava, mais reação se obtinha de políticos e intelectuais conservadores locais, os quais não a viam como produto e fim de seus anseios de projeção política e de formação de intelectuais da burguesia regional. Mas até que ponto, de fato, os professores da FAFI, por mais progressistas que fossem, conseguiram isolá-la das determinações e ditames do capitalismo, em suas mais diversas facetas? Ou mesmo, o quanto eles tinham o propósito de torná-la uma instituição de superação da educação capitalista?

Defender mudanças políticas, sociais e culturais no Brasil, ensinar conteúdos críticos e falar das perspectivas socialistas não garantiam, por si só, a formação de revolucionários ou 
mesmo, não tornava a FFCL de São José do Rio Preto um centro comunizador. Incentivar a participação dos estudantes em projetos de educação popular e valorização da cultura e arte nacionais ainda menos: educava-se mais para a aquisição de uma identidade brasileira do que para uma consciência de classe internacionalizada. Lovisolo (1990, p. 14-15) expõe essa conciliação entre interesses antagônicos, na qual dentro das práticas de educação popular o povo assumiria o lugar da pureza, do pertencimento à terra, enquanto os intelectuais assumiriam uma posição de distanciamento, desenraizamentos, implicando numa "mitologia" entre os seres que seriam os articuladores de um pensamento autônomo, genuinamente brasileiro.

Lovisolo (1990, p. 16-17), quando trata dessa mitificação do processo de construção da educação popular no Brasil, que colocaria os intelectuais não como classe, mas como "expectadores ou aliados", comprometidos com a classe trabalhadora ou com os capitalistas, o que indicaria mas não explicaria, serem os intelectuais "os únicos privilegiados a escolher os aliados e, com isto, o lugar na história que, para os outros está predeterminado". Portanto, os estudantes e professores, ou intelectuais da FAFI, como categorias dominantes dentro da instituição, tendo escolhido aliar-se à classe trabalhadora, estariam submetidos às contingências de seu papel contraditório de representantes do projeto educacional burguês, a serviço do Estado, com domínio linguístico, econômico, cultural e psicológico diferenciado. No entanto, essa opção selou seus destinos, num momento no qual o conhecimento e a criticidade "precisavam" dar lugar ao tecnocratismo e eficiência produtiva.

O que estava em jogo era a transformação da educação num poderoso nicho de reprodução ideológica e mercadológica, afinada com os ditames do capitalismo global. Todas as instituições de ensino superior vinham sendo observadas e monitoradas por órgãos de investigação política, os quais tinham como suporte o complexo IPES/ESG e um projeto bem articulado de infiltração de agentes no movimento estudantil e nas organizações em que a intelectualidade tinha acesso. A polarização política e as doutrinas de controle capitalistas passaram a monitorar todo e qualquer meio de propagação política e vigiavam os jornais, as escolas, as periferias. Todo o conteúdo midiático era controlado, antes mesmo do golpe, pelos aparatos militares e civis burgueses para que veiculassem notícias anticomunismo e defendessem a família, a religião, a propriedade privada e o estado nacional. 
Assim que se instalou a ditadura empresarial civil-militar, várias instituições e entidades foram invadidas, destruídas e desmontadas, não sendo a FFCL de São José do Rio Preto o único caso do interior de São Paulo. Como conta Sanfelice (2008, p. 37; p. 83-84), a sede da UNE foi invadida e incendiada no Rio de Janeiro também no 1ㅇ dia do regime. A UNB sofreu a primeira intervenção, a primeira entre três que ocorreram durante o regime. Essa ocorreu em 9 de abril, quando tropas do exército do Mato Grosso sitiaram a universidade e Anísio Teixeira foi demitido imediatamente da sua direção. O ISEB foi extinto e toda a intelectualidade perseguida. O Plano Nacional de Alfabetização foi liquidado em 14 de abril de 1964, sendo todo o material do Movimento de Educação de Base (MEB) apreendido, as verbas cortadas e os monitores perseguidos. Os Centros de Educação Popular no Nordeste foram fechados e seus integrantes presos e processados. Cunha e Góes (1991, p. 37-38) relatam que os integrantes da Campanha "De pé no chão também se aprendem ler", no Rio Grande do Norte, permaneceram presos por seis meses, os acampamentos foram abandonados e sua biblioteca queimada.

A intervenção e a abertura de sindicância contra os professores da FAFI tornaram-se parte da regra e não exceção. Configurou-se, portanto, numa medida oportunista de construção de provas que não existiam antes, do envolvimento dos professores, que coordenavam a instituição, na articulação de um golpe comunista. A falta de provas materiais para justificar uma intervenção antes de 1964 fez que, com a instalação de um Estado militarizado, pessoas com interesses em recobrar a instituição em nome das classes dominantes locais, pudessem fazê-lo sem que houvesse reação legal amparada pelo governo federal. Além disso, o IPM aberto, assim como as demissões funcionaram como processo repressivo na instituição e na cidade, fazendo com que os estudantes e demais professores da Faculdade tivessem que se manifestar publicamente contra ou a favor do novo regime. Criouse, portanto, o mito para se criar a própria solução para ele: a repressão.

O departamento de Pedagogia foi o mais prejudicado. De acordo com várias testemunhas (professores da USP e ex-estudantes), as disciplinas e direção da faculdade foram assumidas por pessoas com competência duvidosa. As atividades do GRUTA e MPC foram extintas e o CAF foi transformado em DAF após a Lei Suplicy de Lacerda n. 4.464, de 9 de novembro de 1964, quando, de acordo com Sanfelice (2008, p. 93-95), as entidades 
estudantis passaram a ser subordinadas às direções das instituições e órgãos superiores, com sua presidência escolhida e não mais eleita livremente pelos estudantes.

Mesmo com tudo isso, encontraram-se relatos de que os antigos estudantes e alguns professores ainda mantinham o espírito de contestação e recusavam-se a aceitar os ditames da ditadura. Em suplemento especial do jornal local Diário da Região (2012) diz-se que o CAF mantinha seu vínculo com a UNE, mesmo na clandestinidade e isto viria a ser motivo para manter o Sistema Nacional de Informação (SNI) conectado aos rumos da instituição até o final do regime ditatorial.

A organização em departamentos foi mantida até a Reforma Universitária de 1968, os cursos foram reconhecidos e uma comissão criou um novo estatuto em 1966, que após algumas alterações, vigorou de 1968 até 1971, quando foi refeito mediante as novas diretrizes para a educação. A partir de 1966, foi criada a Congregação pelo Conselho Estadual de Educação e a faculdade foi enquadrada, definitivamente, no Sistema de Institutos Isolados, sendo mais tarde, em 1976, incorporada ao projeto da Universidade do Estado de São Paulo "Júlio de Mesquita Filho", sem o curso de Pedagogia, mas com uma história que o regime obscurantista não conseguiria apagar.

\section{Referências}

ATTAB, Z. A. A experiência da Reforma Universitária na Faculdade de Filosofia, Ciências e Letras de São José do Rio Preto (1959-1964). Tese (Doutorado em Educação) - Faculdade de Filosofia, Ciências e Letras de São José do Rio Preto, São José do Rio Preto-SP, 1973.

BRASIL. Exército Brasileiro. Inquérito Policial Militar. Justiça Militar do 10 Distrito Naval da 4ạ Zona Aérea. 1971.

BRASIL. Presidência da República. Ato Institucional n.1, de 9 de abril de 1964. Disponível em: <http://www.planalto.gov.br/ccivil 03/AIT/ait-01-64.htm>. Acesso em: 12 ago. 2018.

BRASIL. Presidência da República. Lei n. 1802, de 5 de janeiro de 1953. Disponível em: <http://legislacao.planalto.gov.br/legisla/legislacao.nsf/Viw Identificacao/lei 1.802-1953>. Acesso em: 12 ago. 2013.

SÃO PAULO. Arquivo Público do Estado de São Paulo. Memórias Reveladas. Disponível em: <http://www.arquivoestado.sp.gov.br/memrev/memrev texto.php >. Acesso em: 12 ago. 2013.

CUNHA, L. A.; GOES, M. O golpe na educação. 7. ed. Rio de Janeiro: Jorge Zahar, 1991.

DIÁRIO DA REGIÃO. Suplemento Especial. Dossiê Ditadura. São José do Rio Preto, 8 de julho de 2012. Disponível em: <https://flip.diariodaregiaodigital.com.br>. Acesso em: 8 ago. 2018. 
DREIFUSS, R. A. 1964: A conquista do Estado. Ação Política, Poder e Golpe de Classe. 3. ed. Petrópolis: Vozes, 1981.

FERNANDES, F. Universidade Brasileira: reforma ou revolução? São Paulo: Alfa-Ômega, 1975.

FLORIDO, C. M. Da efervescência cultural ao obscurantismo ditatorial: a história da Faculdade de Filosofia, Ciências e Letras de São José do Rio Preto sob o olhar da intervenção de 1964. Dissertação (Mestrado em Educação) - Universidade Estadual de Campinas, Campinas-SP, 2013.

LOPES, S. F.; SPARVOLI, L. P. A Faculdade de Filosofia, Ciências e Letras de São José do Rio Preto (1955 a 1964): o estudo introdutório de uma instituição escolar. Cadernos CEDEM, Marília, v. 2, n. 2, p. 91-103, 2011. Disponível em:

<http://www2.marilia.unesp.br/revistas/index.php/cedem/article/view/1603/1375>. Acesso em: 8 ago. 2018.

LOVISOLO, H. Educação Popular: maioridade e conciliação. Salvador: UFBA/Empresa Gráfica da Bahia, 1990.

OLIVEIRA, N. R. Sapere Aude: a Faculdade de Filosofia, Ciências e Letras de São José do Rio Preto no período de 1957-1964. Dissertação (Mestrado em Educação) - Universidade Federal de São Carlos, São Carlos-SP, 1989.

SANFELICE, J. L. Movimento Estudantil: a UNE na resistência ao golpe de 1964. 2. ed. Campinas: Alínea, 2008.

SCOCUGLIA, A. Justiça Fardada e Educação Subversiva (1964-1969): IPM e representação dos vencedores e vencidos. In: VII SEMINÁRIO NACIONAL DE ESTUDOS E PESQUISA - HISTEDBR. Anais [...]. Campinas, jul. 2006. p. 1-18.

TRAGTENBERG, M. Delinquência Acadêmica. In: (org.). Sobre Educação, Política e Sindicalismo. 2. ed. São Paulo: Editores Associados; Cortez, 1990. (Coleção teoria e práticas sociais, v. 1).

VAIDERGORN, J. As Seis Irmãs: as faculdades de Filosofia, Ciências e Letras - Institutos Isolados de Ensino Superior do Estado de São Paulo - 1957-1964. Alguns subsídios interpretativos para o estudo do ensino superior do Estado de São Paulo. Tese (Doutorado em Educação) -Universidade Estadual de Campinas, Campinas-SP, 1995.

WANDERLEY, E. K. C. A Institucionalização da Repressão Judicial na Ditadura Civil-Militar Brasileira. In: ASSOCIAÇÃO BRASILEIRA DE CULTURA POPULAR. Anais do Seminário Intermediário da ABCP, 2009. p. 1-17. Disponível em:

<http://www.sinteseeventos.com.br/abcp/trabalho ErikaWanderley.pdf $>$. Acesso em: 8 ago. 2018. 